\title{
Controladoria: a utilização de indicadores de controle para tomada de decisão numa pequena empresa do ramo farmacêutico em Divinópolis-MG
}

\author{
Valdilene Gonçalves Machado Silva - valdilene.machado@uemg. \\ Universidade do Estado de Minas Gerais (Uemg). \\ Patrícia Cristina Pereira - patrícia.c.pereira2012@gmail.com. \\ Faculdade de Ciências Econômicas, Administrativas e Contábeis de Divinópolis (Faced) \\ Letícia Goulart de Sousa - leticiagoulartsousa@gmail.com. \\ Faculdade de Ciências Econômicas, Administrativas e Contábeis de Divinópolis (Faced) \\ Wellinton Geraldo Vital - wellinton.vital@ hotmail.com. \\ Faculdade de Ciências Econômicas, Administrativas e Contábeis de Divinópolis (Faced)
}

\begin{abstract}
Resumo
As micro e pequenas empresas têm papel fundamental na economia brasileira e, para que sobrevivam num mercado altamente globalizado, onde a concorrência acirrada pode trazer riscos e incertezas, é necessária a utilização de ferramentas que otimizem o processo decisório, o que influencia diretamente no desempenho da empresa. Assim, o principal objetivo deste trabalho é identificar e analisar como os indicadores de controle podem contribuir para tomada de decisões mais seguras numa empresa de pequeno porte do ramo farmacêutico. Realizou-se uma pesquisa descritiva com abordagem qualitativa. Os dados foram levantados mediante pesquisa documental e entrevista semiestruturada com o principal gestor da empresa. Constatou-se a necessidade e importância da utilização de indicadores de controle, pois eles demonstram a real situação da empresa, fornecendo informações seguras e importantes, até então desconhecidas pela empresa, reduzindo as incertezas no processo decisório, além de contribuir para o aumento da eficiência, competitividade e melhoria dos resultados.
\end{abstract}

Palavras-chaves: pequena empresa, indicadores de controle, tomada de decisões.

\begin{abstract}
Micro and small enterprises play a key role in the Brazilian economy and, to survive in a highly globalized market, where fierce competition may involve risks and uncertainties, the use of tools that optimize the decision-making process is needed, which directly influences the performance of company. Thus, the main objective of this work is to identify and analyze how the control indicators can contribute to making safer decisions in a small pharmaceutical company. We conducted a descriptive research with a qualitative approach. The data were collected through documentary research and semi-structured interviews with the main manager of the company. It was found the need and importance of using control indicators, as they demonstrate the real situation of the company, providing secure and important information that are nowadays unknown by company to reduce uncertainty in decision-making and contribute to increased efficiency, competitiveness and improved results.
\end{abstract}


Key words: small business, control Indicators, decision making.

\section{Introdução}

As micro e pequenas empresas (MPEs) ocupam um papel de suma importância na economia brasileira, devido, entre outros fatores, de sua participação relevante no crescimento do produto interno bruto (PIB) do país e da sua contribuição na geração de emprego e renda. Segundo o Serviço Brasileiro de Apoio à Micro e Pequenas Empresas (Sebrae) (2014), elas são responsáveis por 52\% dos empregos com carteira assinada e representam $27 \%$ do PIB. Para sua sobrevivência num mercado altamente globalizado, em que a concorrência extremamente competitiva pode trazer riscos e incertezas, é necessária a utilização de ferramentas que contribuam para a otimização do processo decisório. É papel da controladoria auxiliar a gestão da empresa na busca desse resultado pelo acompanhamento e controle das informações necessárias para tomada de decisão.

Segundo Oliveira, Peres Junior e Silva (2013), a controladoria é responsável por acompanhar informações operacionais, financeiras e contábeis de uma organização, sendo os indicadores de controle ferramentas que auxiliam neste propósito. Para Padoveze (2012), indicadores são métricas financeiras e não financeiras utilizadas para controle de gestão e de desempenho organizacional. Para Rolim Henrique e Rolim Francisco (2013), os indicadores têm, como objetivo primordial, o auxílio na tomada de decisão, para isso se baseiam em fatos e dados que possibilitam planejar ações preventivas. Assim, a questão central a ser respondida é: como os indicadores de controle podem auxiliar na tomada de decisão de uma pequena empresa do ramo farmacêutico?

Quando uma empresa utiliza indicadores, tem mais chances de sobreviver no mercado, pois, por meio de informações mais precisas e uteis, ela consegue minimizar as incertezas na tomada de decisão e planejar melhor suas ações, influenciando diretamente o seu desempenho. Assim, o objetivo desta pesquisa é identificar e analisar como os indicadores de controle podem contribuir para a tomada de decisões numa empresa de pequeno porte do ramo farmacêutico.

A escolha do tema se justifica pela necessidade de informações confiáveis, relevantes e em tempo hábil para a tomada de decisões mais seguras, o que contribui para otimização dos resultados e a sobrevivência das Micro e Pequenas Empresas (MPEs). Portanto, este trabalho é de suma importância, já que, contribuirá para um melhor direcionamento da gestão da empresa, colaborando assim, para o aumento da eficácia organizacional.

\section{Revisão bibliográfica}

A seguir são apresentadas as principais ideias de autores que escreveram sobre o tema tratado.

\subsection{Importância das micro e pequenas empresas}

As MPEs exercem um papel extremamente importante no Brasil, pois contribuem para geração de emprego e renda e para o crescimento econômico. Conforme o artigo 2. ${ }^{\circ}$ da Lei Complementar n..$^{\circ} 139$, de 10 de novembro 2011, são consideradas

(...) microempresas ou empresas de pequeno porte a sociedade empresária, a sociedade simples, a empresa individual de responsabilidade limitada e o empresário a que se refere o art. 966 da Lei n.o 10.406, de 10 de janeiro de 2002 (Código Civil) (...) desde que:

I - no caso da microempresa, aufira, em cada ano-calendário, receita bruta igual ou inferior a $\mathrm{R} \$ 360.000,00(\ldots)$; e

II - no caso da empresa de pequeno porte, aufira, em cada ano-calendário, receita bruta superior a $\mathrm{R} \$ 360.000,00$ (...) e igual ou inferior a $\mathrm{R} \$ 3.600 .000,00$ (...). (BRASIL, 2011.) 


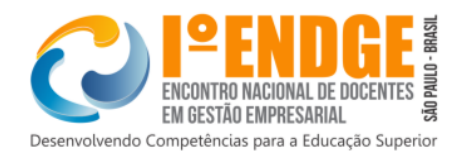

Para o Sebrae (2013), o crescimento do número de MPEs, agregado à competitividade, tende a impactar de forma significativa a economia brasileira pela geração de mais empregos, melhoria dos salários, aumento no recolhimento de impostos e bem-estar social. Em 1985 os pequenos negócios representavam 21\% do PIB; em 2001 23,2\%; e em 2011 chegou a atingir 27\%, reforçando sua importância para a economia brasileira (SEBRAE, 2014).

\subsection{Controladoria}

$\mathrm{O}$ aumento da complexidade no gerenciamento das empresas tem ocasionado maior demanda por controles de gestão eficientes. Assim, o objetivo da controladoria é auxiliar no controle das atividades da empresa, monitorando permanentemente todas as etapas do processo de gerenciamento. Oliveira, Peres Junior e Silva (2013) entendem a controladoria como o departamento responsável pelo acompanhamento de todas as informações operacionais, financeiras e contábeis de determinada entidade, atuando na integração de decisões das diversas áreas da empresa em prol do objetivo organizacional. Para Bianchi, Backes e Giongo (2006), a controladoria atua como elemento colaborador, fornecendo informações para as demais áreas da empresa e possibilitando a execução de ações mais adequadas.

A controladoria é responsável por auxiliar a empresa no controle de seus processos, sendo de sua competência gerar indicadores financeiros e não financeiros que forneçam ao gestor informações dos ambientes interno e externo da empresa (DIAS, 2002). Assim, é função da controladoria o acompanhamento de todas as informações, objetivando elaborar um sistema de planejamento e controle para projetar e simular resultados operacionais, econômicos e financeiros da organização.

\subsection{Contribuição dos indicadores de controle para tomada de decisões}

Informações corretas são essenciais para a tomada de decisões mais eficazes. Para Barbosa (2010), decisões são escolhas de ações a serem implementadas para alcançar objetivos. Trata-se de um processo onde é identificado o problema a ser resolvido e a sua solução. É necessário o gestor cercarse de informações úteis para reduzir as incertezas do processo de tomada de decisão. Uma ferramenta da controladoria para esse fim são os indicadores de controle, que são utilizados na busca do controle eficiente de informações, para facilitar o processo decisório. Takashina e Flores (1996) afirmam que os indicadores são importantes para o controle, pois os seus resultados colaboram não só para a análise do desempenho organizacional, mas, também, para tomada de decisões e replanejamento.

Na opinião de Barbosa (2010), a tomada de decisão nas empresas, independentemente do seu porte, implica diretamente em custos, perdas, gastos e ganhos. Portanto, toda decisão pode ser considerada uma decisão financeira. Oliveira, Peres Junior e Silva (2013) ressaltam que as medidas financeiras indicam se as estratégias implementadas pela empresa estão contribuindo para a otimização dos resultados.

Indicadores financeiros, como o prazo médio de pagamento (PMP) e prazo médio de recebimento (PMR) são importantes para a empresa conhecer e administrar melhor a sincronização entre recebimentos e pagamentos. Para Assaf Neto (2012), PMP é o tempo médio em que a empresa efetua o pagamento de suas compras, e o PMR, é o tempo médio em que recebe o pagamento de suas vendas.

A comparação entre PMP e PMR pode evidenciar uma situação desfavorável, se a empresa trabalhar com um PMP maior que o PMR, podendo ocasionar problemas de liquidez, se não houver capital de giro suficiente para cumprir com suas obrigações financeiras. Assaf Neto (2012) define liquidez como a capacidade da empresa de pagar, tempestivamente, suas dívidas e recomenda que o prazo de recebimento das vendas seja reduzido para garantir recursos disponíveis, não só para pagamento de dívidas, mas, também, para investimento em aplicações rentáveis. A falta de liquidez pode gerar aumento de despesas financeiras, impossibilidade de comprar a prazo e conseguir empréstimos bancários.

O prazo médio de estocagem (PME) e giro de estoque também são indicadores importantes, pois, segundo Pozo (2010), a rotatividade do estoque, além de facilitar a análise das operações da empresa, também é considerada modelo mundial de diagnóstico e comparação. Afirma ainda que, quanto maior 
o giro de estoque, mais adequada será a gestão logística da organização, pois estará contribuindo para redução de custos e aumento de competitividade, e que, no Brasil, o giro de estoque das empresas está em torno de catorze vezes ao ano. Hoji (2012) explica que as empresas buscam aumentar o giro de estoque, pois, quanto mais rápidas forem as vendas, maiores serão as possibilidades de aumento da lucratividade.

De acordo com Guerra, Rocha e Corrar (2007), a estrutura de custo influencia de forma direta o lucro da organização. Muller e Antonik (2008) acreditam que a lucratividade é extremamente importante para as empresas sobreviverem e é de interesse, não só dos sócios, mas, também, dos fornecedores e instituições financeiras. Ribeiro, Fernandes e Kaspczak (2014) ressaltam que os índices de lucratividade auxiliam as empresas na identificação dos seus resultados e da compatibilidade desses resultados com o setor em que ela atua e, em caso de resultados insatisfatórios, indicam os fatores que contribuíram para redução dos lucros.

Considerando a necessidade de maior eficiência no processo de gestão, as empresas começaram a se preocupar também com medidas não financeiras, antes o foco era somente nas medidas financeiras. Padoveze (2012) afirma que, com a disseminação da concepção de controle de qualidade, baseada em medidas não financeiras, as empresas obtiveram uma maior conscientização da importância da utilização de indicadores que mensurem processos e atividades-chaves para complementar os indicadores financeiros.

É importante, entre outros, a análise de indicadores como o de perdas e de produtividade, considerando que têm impacto nos custos da empresa e consequentemente na sua lucratividade. Segundo Nascimento e Cavenaghi (2008), o indicador de produtividade de equipe relaciona a produção ao número de funcionários necessários para o processo. A redução desse índice pode aumentar os custos operacionais da empresa. Pessanha et al. (2010) definem custo operacional como os custos ligados à mão de obra, aos serviços e materiais das operações desenvolvidas pela empresa.

Diante dos fatores descritos, entende-se que a utilização de indicadores não financeiros associados aos financeiros contribui para a empresa identificar seus pontos fortes e fracos e, assim, tomar decisões mais seguras, para melhorar seu desempenho atual e futuro, e, alcançar os objetivos propostos. No Quadro 1 estão relacionados os indicadores de rotação e rentabilidade abordados neste trabalho.

\begin{tabular}{|l|c|}
\hline Índices & Fórmulas \\
\hline Giro do estoque & $\frac{\text { Custos dos produtos vendidos }}{\text { Saldo médio dos estoques }}$ \\
\hline Prazo médio de estocagem & $\frac{\text { Saldo médio dos estoques } \times \mathrm{N}}{\text { Custo dos produtos vendidos }}$ \\
\hline Prazo médio de recebimento de vendas & $\frac{\text { Saldo médio das contas a receber } \times \mathrm{N}}{\text { Receita op. bruta }- \text { devoluções e abatimentos }}$ \\
\hline Prazo médio de pagamento de fornecedores & $\frac{\text { Saldo médio de fornecedores } \times \mathrm{N}}{\text { Compras brutas }}$ \\
\hline Margem líquida & $\frac{\text { Lucro líquido }}{\text { Receita líquida }}$ \\
\hline
\end{tabular}

Quadro 1 - Indicadores de rotação e rentabilidade

Fonte: Hoji (2012, p. 281).

\section{METODOLOGIA}


O objetivo desta pesquisa é identificar e analisar como os indicadores de controle podem contribuir para a tomada de decisões numa empresa de pequeno porte do ramo farmacêutico. Para o alcance deste objetivo, realizou-se uma pesquisa descritiva, pois, a proposta foi descrever como os indicadores de controle podem contribuir para a tomada de decisões mais seguras. Para Gil (2008), as pesquisas do tipo descritivas têm, como objetivo principal, demonstrar os aspectos de uma determinada população ou fenômeno ou, então, determinar ligações entre as variáveis.

Quanto à forma de abordagem é uma pesquisa qualitativa, pois não houve a utilização de métodos e técnicas estatísticas, sendo que "O processo e seu significado são os focos principais da abordagem." (SILVA; MENEZES, 2005, p. 20.)

Realizou-se um estudo de caso, pois o interesse foi fazer um "(...) estudo profundo e exaustivo de um ou poucos objetos, de maneira que permita seu amplo e detalhado conhecimento" (Gil, 2002, p. 54). A pesquisa bibliográfica foi elaborada com base em material já publicado, composto principalmente de livros e artigos científicos, com o objetivo de aprofundar o conhecimento sobre o tema.

Os dados foram coletados através de uma entrevista semiestruturada com o principal gestor da empresa e pela pesquisa documental, pois, de acordo com Vergara (2009), apesar da entrevista semiestruturada ter um foco, ela permite inserções, exclusões e até mesmo mudanças nas perguntas ao longo do processo, dependendo das respostas do entrevistado. Os dados levantados pela entrevista foram analisados com base no referencial teórico.

A pesquisa documental se baseou em dados primários, extraídos de relatórios gerenciais, que foram transformados em índices e estes em gráficos com o auxílio do programa Excel para melhor compreensão. Por meio dos índices foi possível apontar pontos fortes e fracos da empresa.

\section{ANÁLISE DOS RESULTADOS}

Este estudo de caso foi realizado numa empresa privada, de pequeno porte, do ramo farmacêutico, que trabalhava com revenda de medicamentos industrializados e a produção e comercialização de medicamentos manipulados. Iniciou suas atividades no ano 2000 e contava com 35 colaboradores no seu quadro de funcionários.

A partir da entrevista, obteve-se que relatórios gerenciais eram utilizados para controle da empresa. Deles eram extraídos dados relacionados ao faturamento, estoque, custo e lucro da empresa, porém o custo abrangia somente o custo gerado pela compra de mercadorias e matérias-primas, o que o tornava impreciso, por não considerar gastos com mão de obra.

As despesas operacionais também não eram analisadas, pois o gestor não possuía um relatório que incluísse esse tipo de gasto, o que interferia nas informações relacionadas ao lucro da empresa. $\mathrm{O}$ fato de não ser considerado, na análise gerencial, os gastos com despesas operacionais e mão de obra fez com que a situação da empresa estivesse sendo retratada de forma equivocada para o gestor. Portanto, pode-se concluir que a ineficiência dos controles efetuados pela empresa era uma fragilidade importante, pois podia comprometer a qualidade das decisões tomadas.

Os relatórios gerenciais eram fontes de informações para o gestor, deles eram extraídas informações importantes para a tomada de decisão. Assim, deficiências nessas informações poderia comprometer de forma significativa o processo decisório, pois o gestor estava trabalhando com dados incompletos, $o$ que resultava em informações inconsistentes, que podiam levá-lo à tomada de decisões inadequadas, prejudicando, dessa forma, a sustentabilidade da empresa.

Segundo o entrevistado, como a empresa não elaborava nenhum tipo de planejamento, as decisões eram demandas a partir de problemas que surgiam no dia a dia. Quando esses problemas eram identificados, levantava-se as informações necessárias para tomada de decisão, que normalmente estavam disponíveis no sistema de informação gerencial utilizado pela empresa, realizava-se a análise dos dados levantados e, logo após, concluía-se o processo, optando pela decisão considerada mais 
acertada. Observa-se aí, mais uma fragilidade da empresa, pois estava sujeita a tomar decisões incorretas por utilizar um sistema de informações gerenciais, como fonte de informações para tomada de decisões, cujas informações eram inconsistentes.

O gestor ressaltou que as principais informações utilizadas para a tomada de decisão eram o custo do produto e da mercadoria, o saldo e a movimentação de estoque. Informações sobre custo eram utilizadas frequentemente, pois influenciavam a compra e venda de produtos e mercadorias. Já as informações de estoque, como saldo e movimentação, auxiliavam a empresa na identificação do ponto de pedido e no giro de estoque de determinados produtos, porém, a empresa tinha controle somente dos itens de estoque que julgava mais importante por possuírem maior lucratividade.

O entrevistado desconhecia qual custo tinha maior impacto sobre a receita líquida da empresa. Assim, foi interesse desta pesquisa identificá-lo. O Gráfico 1 demonstra os custos e despesas que compunham os gastos totais da empresa e o impacto deles sobre sua receita líquida.

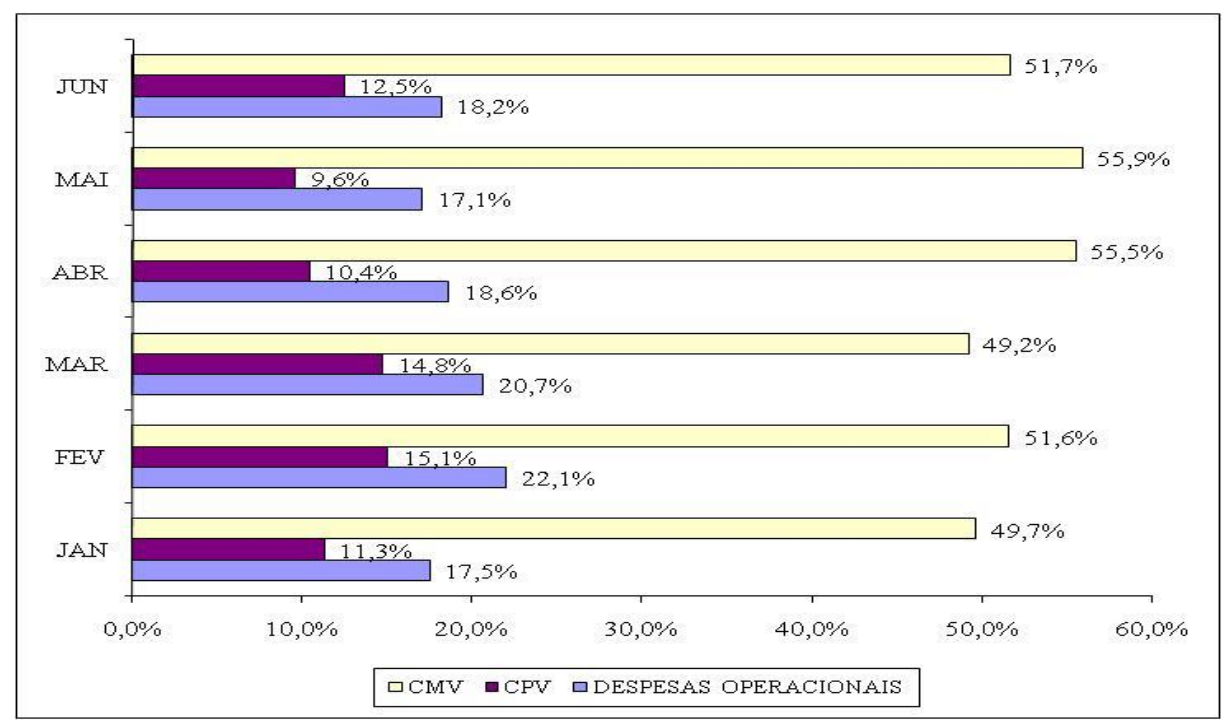

Gráfico 1 - Impacto dos custos e despesas sobre a receita líquida da empresa Fonte: Dados da pesquisa.

Pode-se concluir, conforme demonstrado no Gráfico 1, que o maior impacto sobre receita líquida no período analisado foi o custo das mercadorias vendidas (CMV), que no mês de maio representou $55,9 \%$ da receita líquida. Já as despesas operacionais compostas de despesas administrativas e de vendas tiveram um impacto menor, pois representaram, no máximo, $22,1 \%$ da receita líquida, mês de fevereiro. O custo dos produtos vendidos (CPV), constituído pelos gastos com mão de obra direta, gastos gerais de fabricação e custo de matérias-primas e embalagens teve o menor impacto sobre a receita líquida, comprometeu, no máximo, $15,1 \%$ da receita líquida, mês de fevereiro.

Para Guerra, Rocha e Corrar (2007), a estrutura de custos influencia, de forma direta, o lucro da organização. Considerando a relação entre custo e lucro, é importante que a empresa desenvolva ações que possam aumentar seu poder de compra junto aos fornecedores, com o objetivo de obter descontos maiores nas compras das mercadorias, reduzindo, assim, o CMV e aumentando, consequentemente, a sua lucratividade.

Outra informação importante para tomada de decisão está relacionada ao estoque. Obteve-se que, prazo médio de estocagem (PME) e o giro de estoque, eram levantados por meio de dados coletados nos relatórios gerenciais da empresa, porém, percebeu-se que a empresa não tinha conhecimento satisfatório do seu giro mensal de estoque e nem do prazo médio de estocagem de mercadorias e matérias-primas, assim, esta era mais uma fragilidade nos controles da empresa. 
Calculou-se, com os dados levantados através dos relatórios gerenciais da empresa, o PME e o giro de estoque. Constatou-se que o PME foi menor no mês de março, 48 dias, e atingiu 54 dias no mês de fevereiro. Trata-se de um índice importante porque, conhecendo esse prazo, a empresa poderá definir ações para reduzi-lo, pois de acordo com Assaf Neto (2012), quanto maior o prazo de estocagem de matérias-primas e mercadorias, maior também será a necessidade de investimentos em estoque. Assim, quanto maior o investimento em estoque, maior será o seu custo de oportunidade, de armazenagem e também o risco de liquidez, pois, grande parte do capital de giro estará sendo direcionado para investimento em estoque e, a empresa poderá não ter caixa suficiente para cumprir suas obrigações com fornecedores, funcionários e pagamento de impostos.

Para melhor entendimento da situação, analisou-se separadamente os PMEs das matérias-primas e das mercadorias. Identificando-se que, no período analisado, as matérias-primas permaneceram em média cinquenta dias em estoque e as mercadorias, 51 dias. $\mathrm{O}$ gestor relatou que as matérias-primas eram compradas nas quantidades mínimas estabelecidas pelos fornecedores e que algumas mercadorias, por terem sido compradas em lotes maiores, para obtenção de maiores descontos em seus preços, permaneciam mais tempo estocadas, gerando assim, maior custo de estocagem.

O fato da empresa estar inserida num setor bastante competitivo e ter como concorrentes grandes redes, que normalmente possuíam maior poder de negociação com os fornecedores, fez com a empresa optasse por comprar em maior quantidade para obter descontos maiores e, assim, poder oferecer preços menores aos seus clientes, com o objetivo de vender mais e manter a empresa competitiva no mercado.

Observou-se que a empresa não realizava análise financeira para verificar se os descontos obtidos nas compras de lotes maiores de mercadorias compensavam o aumento dos custos de armazenagem, o que foi considerado outra fragilidade da empresa. Entende-se que seja necessário fazer uma análise da relação custo-benefício da compra de lotes maiores, assim como, um controle rígido dos itens de estoque, principalmente, das mercadorias, já que eram os itens que mais impactavam nos custos. No Gráfico 2 está apresentado o giro de estoque da empresa.

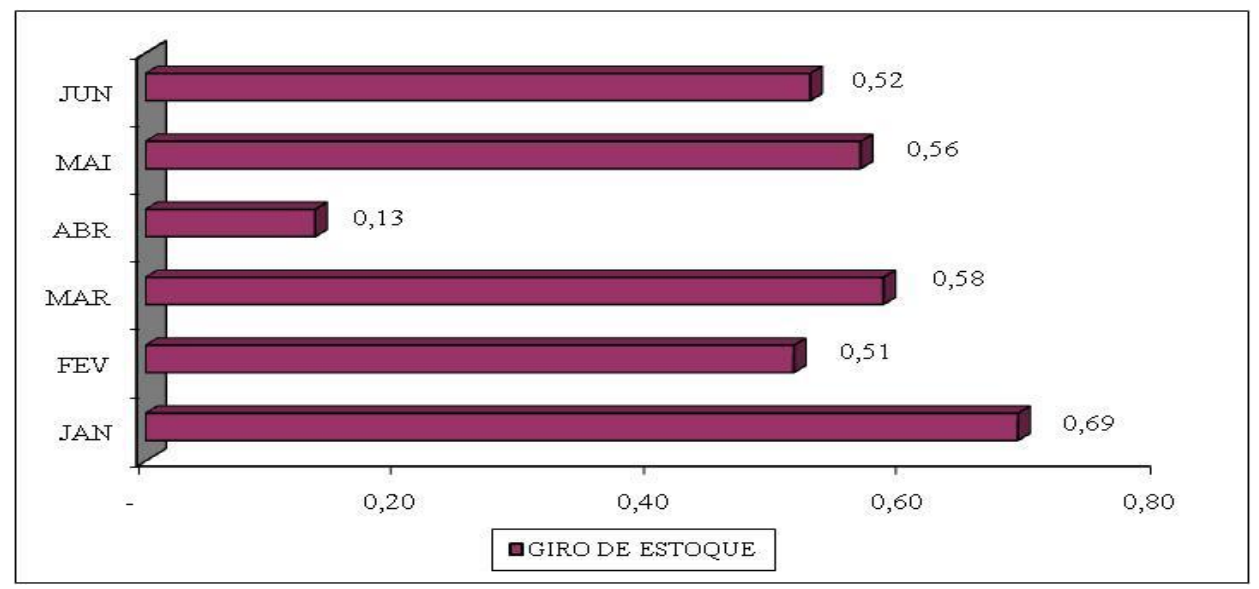

Gráfico 2 - Giro de estoque mensal da empresa Fonte: Dados da pesquisa.

Em relação ao giro de estoque, Pozo (2010) afirma que, quanto maiores forem seus resultados, mais adequada será a gestão logística da organização; haverá também redução de custos e aumento de competitividade. No Brasil, o giro de estoque das empresas está em torno de catorze vezes ao ano.

Analisando-se o Gráfico 2, nota-se que a empresa teve seu menor giro de estoque no mês de abril, girou apenas 0,13 vezes, já em janeiro, a empresa conseguiu girar 0,69 vezes, ainda assim, não atingiu a média nacional de 1,17 vezes ao mês, o que demonstra ineficiência da empresa nesse processo. 
O índice de perda também foi analisado e notou-se que este não expressa valores significativos perante a receita líquida. No período analisado as perdas não atingiram $1 \%$ da receita líquida. Pode-se considerar que o controle sobre as perdas era eficiente e caracterizava uma potencialidade da empresa.

O Gráfico 3 mostra que o PMP foi maior que o PMR em todos os meses analisados; o que representa uma situação favorável para a empresa, já que conseguia receber suas vendas antes de efetuar o pagamento de seus fornecedores, reduzindo, assim, a sua necessidade de investimento em giro (NIG).

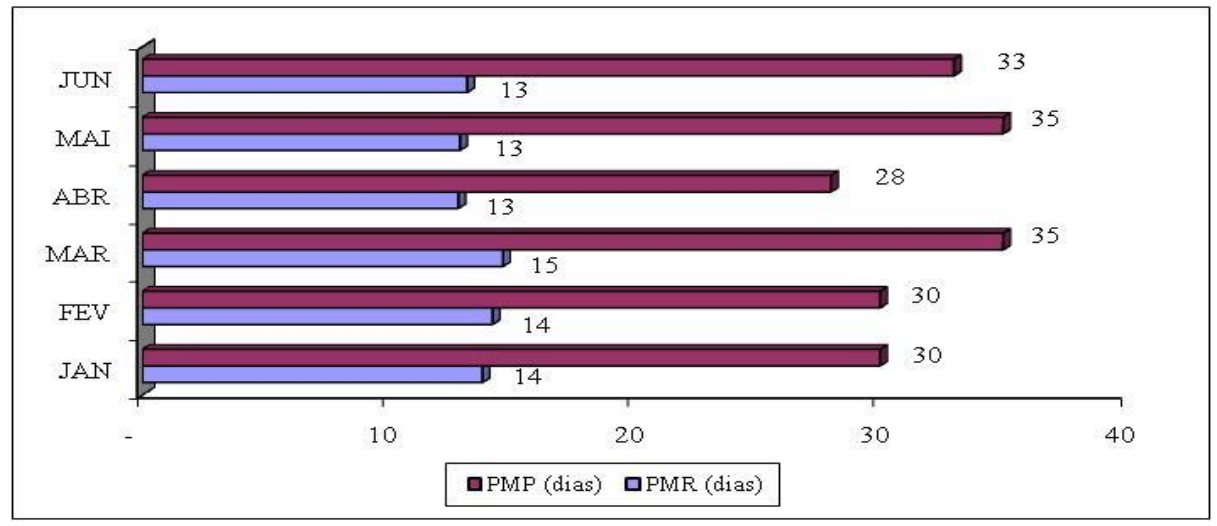

Gráfico 3 - PMP x PMR

Fonte: Dados da pesquisa.

Para Assaf Neto (2012), é importante que a empresa reduza seu PMR, para que haja recursos disponíveis, tanto para pagamento de dívidas, como para investimento em aplicações que sejam rentáveis.

Outro indicador de extrema importância para análise da situação da empresa é a margem líquida.

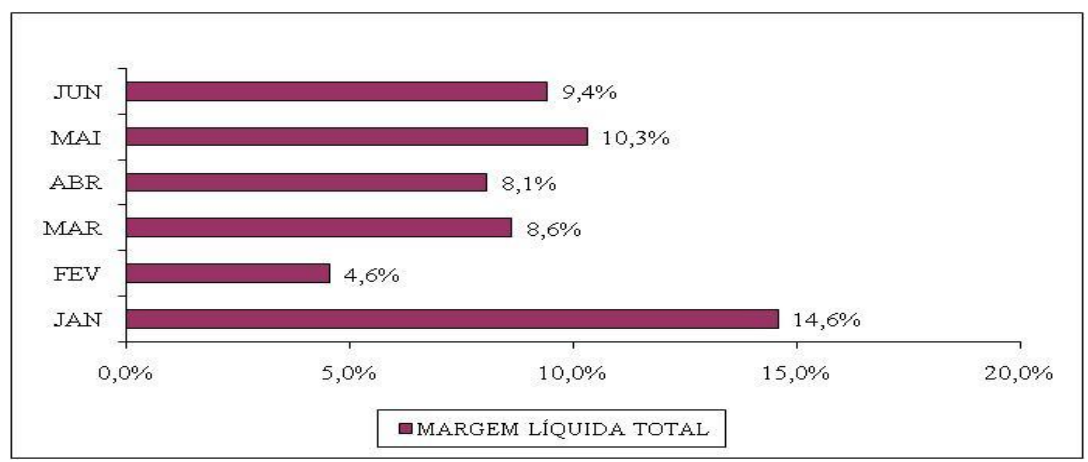

Gráfico 4 - Margem líquida total da empresa

Fonte: Dados da pesquisa.

Com o Gráfico 4, é possível perceber que a maior margem líquida ocorreu no mês de janeiro, 14,6\%, seguido pelo mês de maio, $10,3 \%$; já fevereiro foi o mês com menor margem no período analisado, 4,6\%. Observa-se que houve uma oscilação significativa nos índices de margem líquida da empresa.

Pela análise do Gráfico 5 é possível perceber que os medicamentos manipulados geravam maior margem líquida, podendo-se destacar os meses de abril com 54,7\% e maio com 52,2\%, enquanto os medicamentos industrializados chegaram a gerar prejuízo de $9,6 \%$ em abril e de $2,6 \%$ em maio. 


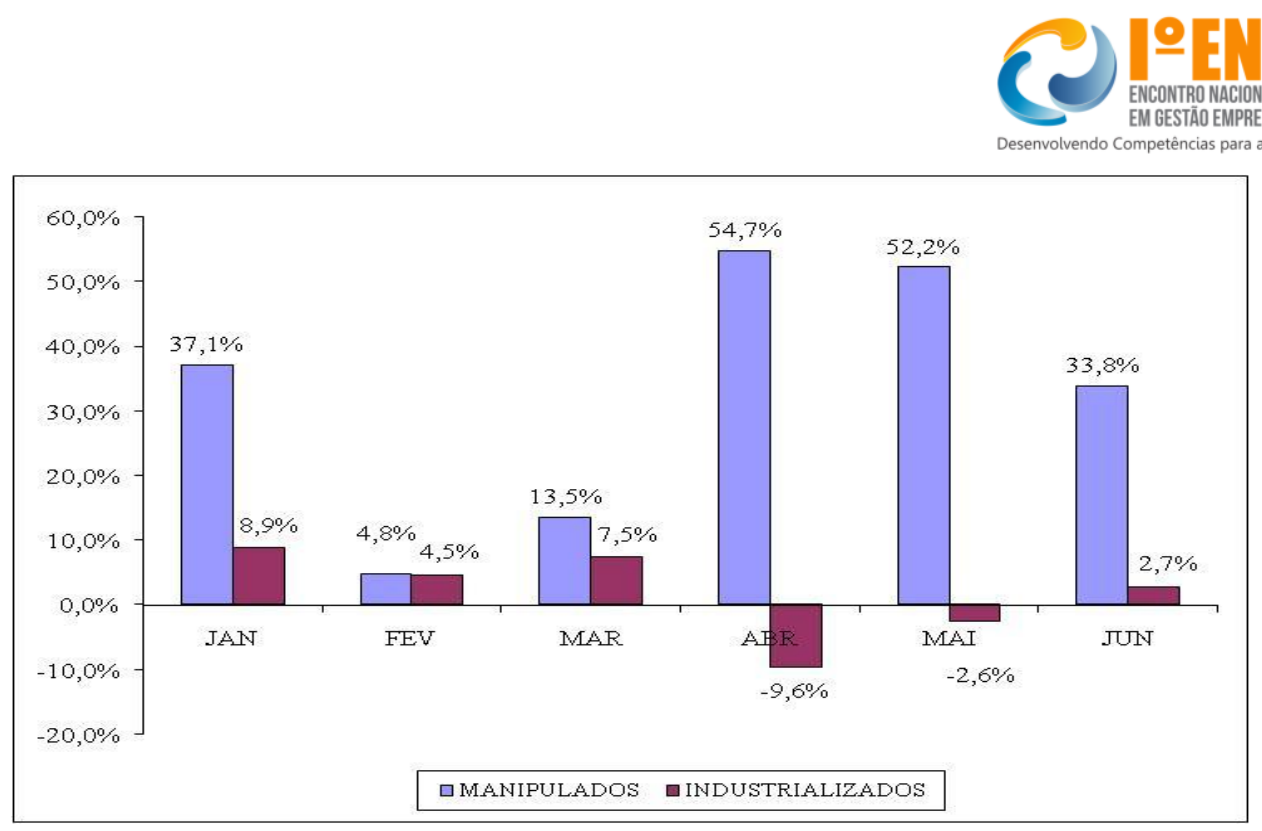

Gráfico 5 - Margem líquida dos medicamentos manipulados e industrializados Fonte: Dados da pesquisa.

O entrevistado esclareceu que os medicamentos industrializados eram vendidos como estratégia de marketing, para atrair clientes para loja. Mesmo gerando prejuízos em determinados meses, eles ajudaram no crescimento da farmácia, pois o cliente ia à loja para comprar medicamentos industrializados e acabava levando o manipulado, graças à relação custo-benefício.

O Quadro 2 apresenta uma síntese das potencialidades e fragilidades encontradas na empresa.

\begin{tabular}{|l|l|}
\hline Potencialidades & Fragilidades \\
\hline PMP maior que o PMR. & $\begin{array}{l}\text { Método de controle baseado em relatórios gerenciais } \\
\text { inconsistentes. }\end{array}$ \\
\hline Baixo índice de perdas. & Processo decisório fundamentado em informações incompletas. \\
\hline $\begin{array}{l}\text { Lucratividade no período } \\
\text { analisado. }\end{array}$ & $\begin{array}{l}\text { Falta de conhecimento da empresa em relação ao seu PME e } \\
\text { giro de estoque. }\end{array}$ \\
\hline & $\begin{array}{l}\text { Ausência de análise financeira para examinar a relação custo- } \\
\text { benefício na compra de lotes maiores de mercadorias. }\end{array}$ \\
\hline & Giro de estoque abaixo do índice médio nacional. \\
\hline
\end{tabular}

Quadro 2 - Potencialidades e fragilidades da empresa

Fonte: Dados da pesquisa.

\section{CONCLUSÕES}

Através da entrevista com o principal gestor da empresa, pôde-se conhecer o método de controle utilizado. Constatou-se que se tratava de um método falho, por se basear em relatórios gerenciais, que não continham informações seguras, porque não consideravam dados importantes, como gastos com mão de obra e despesas operacionais, sendo, portanto, uma fragilidade da empresa.

Como a empresa não fazia planejamento, as tomadas de decisões eram apenas para resolver os problemas do dia a dia e, para isso, utilizavam informações retiradas desses relatórios que não continham informações seguras, o que prejudicava a qualidade do processo decisório. No processo decisório as principais informações demandadas eram o custo do produto e da mercadoria, o saldo e movimentação de estoque, sendo que o custo influenciava a compra e venda de produtos e mercadorias e as informações de estoque, na identificação do ponto de pedido e também no giro de estoque de determinados produtos. 
A partir da análise dos indicadores de controle calculados, constatou-se que o custo de maior impacto no resultado da empresa foi o custo das mercadorias vendidas. Os resultados permitiram perceber também que o giro de estoque representava uma fragilidade da empresa, pois era menor que o índice médio nacional. A margem líquida indicou que a empresa era lucrativa, sendo que os medicamentos manipulados tinham maior margem líquida. As potencialidades identificadas foram o eficiente controle do índice de perdas e a perfeita sincronização entre recebimento e pagamento.

Identificou-se que a empresa não utilizava indicadores de controle para subsidiar a tomada de decisão, e, a partir do que foi demonstrado, conclui-se que eles podem contribuir para a otimização do processo decisório, pois, demonstraram de forma clara a situação da empresa, trazendo informações de extrema importância, até então desconhecidas. Dessa forma, os indicadores de controle podem contribuir para o aumento de eficiência e competitividade da empresa e, assim, para a melhoria dos resultados.

\section{Referências bibliográficas}

ASSAF NETO, Alexandre. Estrutura e análises de balanços: um enfoque econômico-financeiro. 10. ed. São Paulo: Atlas, 2012.

ASSAF NETO, Alexandre. Finanças corporativas e valor. 6. ed. São Paulo: Atlas, 2012.

BARBOSA, Heitor Monteiro. A análise de demonstrativos financeiros para tomada de decisão nas micro e pequenas empresas. Scientia FAER, Olímpia, 2010, v. 2, n. 2, p. 38-52, jan./jun. 2010. Disponível em: <http://www.faer.edu.br/revistafaer/artigos/ edicao2/heitor.pdf>. Acesso em: 20 mar. 2015.

BIANCHI, Márcia; BACKES, Rosemary Gelatti; GIONGO, Juliano. A participação da controladoria no processo de gestão organizacional. Con Texto, Porto Alegre, 2006, v. 6, n. 10, p. 1-23, jul./dez. 2006. Disponível em: <http://seer.ufrgs.br/ConTexto/ article/view/11230>. Acesso em: 20 mar. 2015.

BRASIL. Lei complementar n. ${ }^{0}$ 139, de 2011. Altera dispositivos da Lei Complementar no 123, de 14 de dezembro de 2006, e dá outras providências. Disponível em: < http://www.planalto.gov.br/ccivil_03/leis/LCP/Lcp139.htm >. Acesso em: 9 mar. 2015.

DIAS, Bibiane Borges. O papel da controladoria no suporte do processo de geração de informações voltadas ao controle de gestão operacional em empresa prestadora de serviço de hemodinâmica. 2002.120 f. Dissertação (Mestrado em Engenharia de Produção) - Universidade Federal de Santa Catarina, Florianópolis, 2002. Disponível em: <https://repositorio.ufsc.br/handle/123456789/ 83432>. Acesso em: 25 mar. 2015.

ECKERT, Alex et al. A utilização de índices econômico-financeiros em uma empresa do ramo das autopeças: vislumbrando a internacionalização. In: CONGRESSO VIRTUAL BRASILEIRO ADMINISTRAÇÃO, 8, 2011. Anais... Online: Convibra, 2011. Disponível em: <http://www.convibra.com.br/upload/ paper/adm/adm 2763.pdf>. Acesso em: 19 mar. 2015.

GIL, Antônio Carlos. Como elaborar projeto de pesquisa. 4. ed. São Paulo: Atlas, 2002.

GIL, Antônio Carlos. Métodos e técnicas de pesquisa social. 2. ed. São Paulo: Atlas, 2008.

GITMAN, Lawrence Jeffrey. Princípios de administração financeira. 10. ed. São Paulo: Pearson, 2008.

GUERRA, Almir Rogério; ROCHA, Welington; CORRAR, Luís João. Análise do impacto das variações de receitas nos lucros das empresas com diferentes estruturas de custos. Revista Administração. São Paulo, 2007, v. 42, n. 2, p. 227-238, abr./maio/jun. 2007. Disponível em: <http://www.rausp.usp.br/busca/artigo.asp? num_artigo=1224>. Acesso em: 10 out. 2015.

HOJI, Masakazu. Administração financeira e orçamentária. 10. ed. São Paulo: Atlas, 2012. 
MULLER, Aderbal Nicolas; ANTONIK, Luis Roberto. Análise financeira: uma visão gerencial. São Paulo: Atlas, 2008.

NASCIMENTO, Luiz Gustavo; CAVENAGHI, Vagner. Gestão estratégica e o balanced scorecard: proposta de mapa estratégico para empresas de call center. In: CONGRESSO NACIONAL DE EXCELÊNCIA EM GESTÃO, 4, 2008, Niterói. Anais... Niterói: CNEG, 2008. p.1-25. Disponível em: <http://excelenciaemgestao. org/ Portals/2/documents/cneg4/ anais/T7_0096_0265.pdf>. Acesso em: 1 jul. 2015.

OLIVEIRA, Luís Martins de; PEREZ JUNIOR, José Hernandez; SILVA, Carlos Alberto Santos. Controladoria estratégica. 9. ed. São Paulo: Atlas, 2013.

PADOVEZE, Clóvis Luís. Controladoria estratégica e operacional. 3. ed. São Paulo: Cengage Learning, 2012.

PESSANHA, José Francisco Moreira et al. Avaliação dos custos operacionais eficientes das empresas de transmissão do setor elétrico brasileiro: uma proposta de adaptação do modelo DEA adorado pela Aneel. Pesquisa Operacional, Rio de Janeiro, 2010, v. 30, n. 3, p. 521-545, set/dez. 2010. Disponível em: <http://www.scielo.br/pdf/pope/v30n3/v30n3a02.pdf>. Acesso em: 1 jul. 2015.

POZO, Hamilton. Administração de recursos patrimoniais: uma abordagem logística. 6. ed. São Paulo: Atlas, 2010.

RIBEIRO, Alexandre Luiz Bachi; FERNANDES, Ronei Henrique; KASPCZAK, Márcia Cristina de Mello. Análise econômica e financeira: um estudo de caso em uma empresa que atua no setor metalúrgico sediada em Caxias do Sul no estado do Rio Grande do Sul. In: CONGRESSO BRASILEIRO DE ENGENHARIA DE PRODUÇÃO, 4, 2014, Ponta Grossa. Anais... Ponta Grossa: CONBREPRO, 2014. Disponível em:

<http://www.aprepro.org.br/conbrepro/2014/anais/artigos/eng\%20e/32.pdf>. Acesso em: 30 jun. 2015.

ROLIM, Henrique Sérgio Cavalcanti; ROLIM, Francisco Mozart Cavalcanti. Avaliação de desempenho no setor público mediante aplicação do Balanced Scorecard. Revista Científica Intermeio, Fortaleza, 2013. Disponível em:

$<\mathrm{http} / / /$ www.iesc.edu.br/pesquisa/arquivos/Artigo_BALANCED_SCORECARD.pdf $>$. Acesso em: 20 mar. 2015.

SERVIÇO BRASILEIRO DE APOIO A MICRO E PEQUENAS EMPRESAS (SEBRAE). Micro e pequenas empresas geram $27 \%$ do PIB Brasileiro. 2014. Disponível em:

$<$ http://www.sebrae.com.br/sites/PortalSebrae/ufs/mt/noticias/Micro-e-pequenas-empresas-geram27\%25-do-PIB-do-Brasil>. Acesso em: 25 abr. 2015.

SERVIÇO BRASILEIRO DE APOIO A MICRO E PEQUENAS EMPRESAS (SEBRAE). Participação das micro e pequenas empresas na economia do Brasil. 2014. Disponível em: <http://www.sebrae.com.br/Sebrae/Portal\%20Sebrae/Estudos\%20e\%20Pesquisas/Participacao\%20das $\% 20$ micro\%20e\%20pequenas\%20empresas.pdf>. Acesso em: 25 abr. 2015.

SERVIÇO BRASILEIRO DE APOIO A MICRO E PEQUENAS EMPRESAS (SEBRAE).

Sobrevivência das empresas no Brasil. 2013. Disponível em:

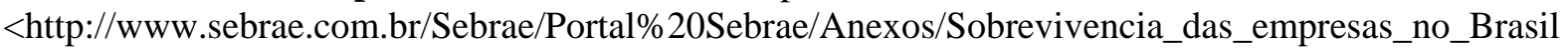
=2013.pdf $>$. Acesso em: 25 abr. 2015.

SILVA, Edna Lúcia da; MENEZES, Estera Muszkat. Metodologia da pesquisa e elaboração de dissertação. 4. ed. rev. e atual. Florianópolis: Ed. da UFSC, 2005. Disponível em:

$<$ https://projetos.inf.ufsc.br/arquivos/Metodologia_de_pesquisa_e_elaboracao_de_teses_e_dissertacoe s_4ed.pdf >. Acesso em: 20 mar. 2015.

TAKASHINA, Newton Tadachi; FLORES, Mario César Xavier. Indicadores da qualidade e do desempenho: como estabelecer metas e medir resultados. 3. ed. Rio de Janeiro: Qualitymark, 1996. 
VERGARA, Sylvia Constant. Métodos de coleta de dados no campo. São Paulo: Atlas, 2009. 